\title{
An approach to use agricultural waste fibre in polymer (polypropylene: PP) for bio-composites applications
}

\begin{abstract}
The mechanical properties of rice husk composites were studied. The range of added rice husk is $(0 \%, 10 \%, 15 \%$, and $20 \%)$ of polypropylene weight and, the rise husk ratio was $10 \%$. Natural fiber extracted from plants has gained attentions owing to their advantages over synthetic polymers. Nowadays composites from natural fibers are among the most keenly required materials. In the present study raw rice husk was treated in order to enhance the properties. The purpose of using annealing method is to increase the rate of reaction. Change in morphology of rice husk was found when treated through SEM technique. The goal of the present study is to show that chemical treatment is an effective method to enhance the properties of rice husk that may be used as reinforcement in polymers to make ecofriendly, lightweight, biodegradable polymer composites. The properties (polypropylene (PP)/ rice husk (RH)) composites were analyzed as a function of the RH amount. All prepared composites showed improved fibers dispersion in the polypropylene matrix. All composites displayed lower elongation of break compared to pure PP. Recently, interest in composite manufacturing has shifted towards the use of natural fibres as reinforcement because of their environmental benefits. The use of a biodegradable matrix is worth considering since this would result in a completely biodegradable composite. In order to assess the most suitable matrix polymer, one must know the properties of the available polymers. Since data tend to be widely scattered over many sources and are very scarce compared to the conventional polymers, it is the purpose of this article to give an overview of the most relevant properties of a range of biodegradable polymers. An overview such as the one given here may provide a useful guide in establishing the best compromise between conflicting property demands. This research work describes the characterization and fabrication of bio-composites. In recent years, the incorporation of natural fibers as reinforcing agent in polymers has gained increasing interest which enhances optimal utilization of natural resources and particularly of renewable resources. Natural fibers have proven to be suitable reinforcement materials for composite; thanks to a combination of good mechanical and thermal properties with environmental advantages such as renewability and bio-degradability, comparable to synthetic fiber reinforced polymer composites. Hence, for these reasons it has not been surprising that the use of natural materials in the production of composites has gained significant importance both in technical applications such as in automotive industry. The effect of rice husk concentration in composite has been analyzed. In order to improve the strength and to reduce the sensitivity to environmental influences, the interfacial adhesion between the natural fiber and the matrix material was improved by chemical treatment of the rice husk.
\end{abstract}

Keywords: composite materials, dynamic mechanical analysis, rice husk polypropylene, DSC, SEM
Volume 2 Issue 5 - 2018

\author{
Sharma J,' Amjad Sajjad, ${ }^{2}$ Unis Bhat, ${ }^{2}$ Singh S' \\ 'Kali Jankalyan Samiti, India \\ ${ }^{2}$ Department of Physics, India
}

Correspondence: Sharma J, Kali Jankalyan Samiti, Bhopal, MP, India, Email janu.sharma87@gmail.com, sharma04j@gmail.com

Received: January 13,2018 | Published: September 28, 2018

\section{Introduction}

A composite material is a combination of two or more materials of which performance characteristics exceed those which are not achievable from its individual components. ${ }^{1}$ The purpose of composites is to allow the new material to have strengths from both materials, often times covering the original materials' weaknesses. Composites are different from alloys because alloys are combined in such a way that it is impossible to tell one particle, element, or substance from the other. The individual materials that make up composites are called constituents. Most composites have two constituent materials: a binder or matrix, and reinforcement (Figure 1). The reinforcement is usually much stronger and stiffer than the matrix, and gives the composite its good properties. The matrix holds the reinforcements in an orderly pattern. When the reinforcements are discontinuous, the matrix also helps to transfer load among the reinforcements. Some common composite materials include concrete, fiber glass, mud bricks, and natural composites such as rock and wood. ${ }^{2}$ Reinforcements basically come in three forms: Particulate, Discontinuous fiber, and Continuous fiber. A particle has roughly equal dimensions in all directions, though it doesn't have to be spherical. Gravel, micro balloons, and resin powder are examples of particulate reinforcements. Reinforcements become fibers when one dimension becomes long compared to others (Table 1). Discontinuous reinforcements (chopped fibers, milled 
fibers, or whiskers) vary in length from a few millimetres to a few centimetres. Most fibers are only a few microns in diameter, so it doesn't take much length to make the transition from particle to fiber. With either particles or short fibers, the matrix must transfer the load at very short intervals (Figure 2). Thus, the composite properties cannot come close to the reinforcement properties. With continuous fibers, however, there are few if any breaks in the reinforcements. Composite properties are much higher, and continuous fibers are therefore used in most high performance components, be they aerospace structures or sporting goods. ${ }^{3}$

Matrix phase basically come in three forms: Metal Matrix, Ceramic Matrix and Polymer Matrix. In general, metals and polymers are used as matrix materials because some ductility is desirable; for ceramic-matrix composites, the reinforcing component is added to improve toughness. ${ }^{4}$ In polymer composites, fibrous materials e.g. synthetic or natural, serve either as filler or as reinforcement by giving strength, stiffness structure and influenced the insulating and dielectric properties, while polymer matrix serves as the adhesive to hold the fibers in place. Natural fibers have been extensively used as reinforcements into polymer matrices as an alternate to the commonly used synthetic fibers like carbon, glass or aramid because of their low-density good mechanical and dielectric properties, abundant availability and bio-degradability. ${ }^{5}$

Generally the properties of composite material are strongly influenced by the properties of its constituents. Various factors that affect the properties of composites are: Fiber dispersion, Orientation and geometry (aspect ratio) of the fibers, the volume fraction of the fiber and Quality of inter face between the polymer matrices and reinforcing fibers. ${ }^{6}$ To obtain good performance composite need good dispersion of the fiber in the polymer matrix is required. Lack of dispersion can results in agglomeration of fibers, which lead to the composite properties falling short of their reinforcing potential. Natural fibers are replacing synthetic fibers as reinforcement in various matrices. The composites so prepared can effectively be used as substitute for wood and also in various other technical fields, e.g. building parts, infrastructure, marine, transportation, and industrial / consumer. $^{?}$

Cellulosic fillers have attracted considerable interest for the reinforcement in thermoplastics such as polypropylene and polyethylene (which melt or soften relatively at lower temperature). Wood and cellulose fibres provide benefits of their high specific strength and stiffness as reinforcements for synthetic polymers. ${ }^{8}$ Rice husk obtained from milling process of rice can be used as filler because of its vast availability. Rice husk roughly contains $35 \%$ cellulose, $35 \%$ hemi cellulose, $20 \%$ lignin and $10 \%$ ash ( $94 \%$ silica), by dry weight basis. From an environmental point of view, the ability to use rice husk is of importance. ${ }^{9}$

Rice husk $(\mathrm{RH})$ is one of the major agricultural residues produced as a byproduct during the rice milling process. Usually it has been a problem for rice farmers due to its resistance to decomposition in the ground, difficult digestion and low nutritional value for animals. Most of the RH produced is either used as a bedding material for animals, burned or used for land filling. Therefore, the development of new polymer composites filled with RH turns out to be a very interesting approach. ${ }^{10}$ Designing of new materials with desired properties is necessary from the application point of view. Composites containing hollow keratin fibres are characterized by low value of electric permittivity due to air present inside. ${ }^{11}$ The aim of this study is to find out the effect of adding rice husk on mechanical properties of polypropylene.

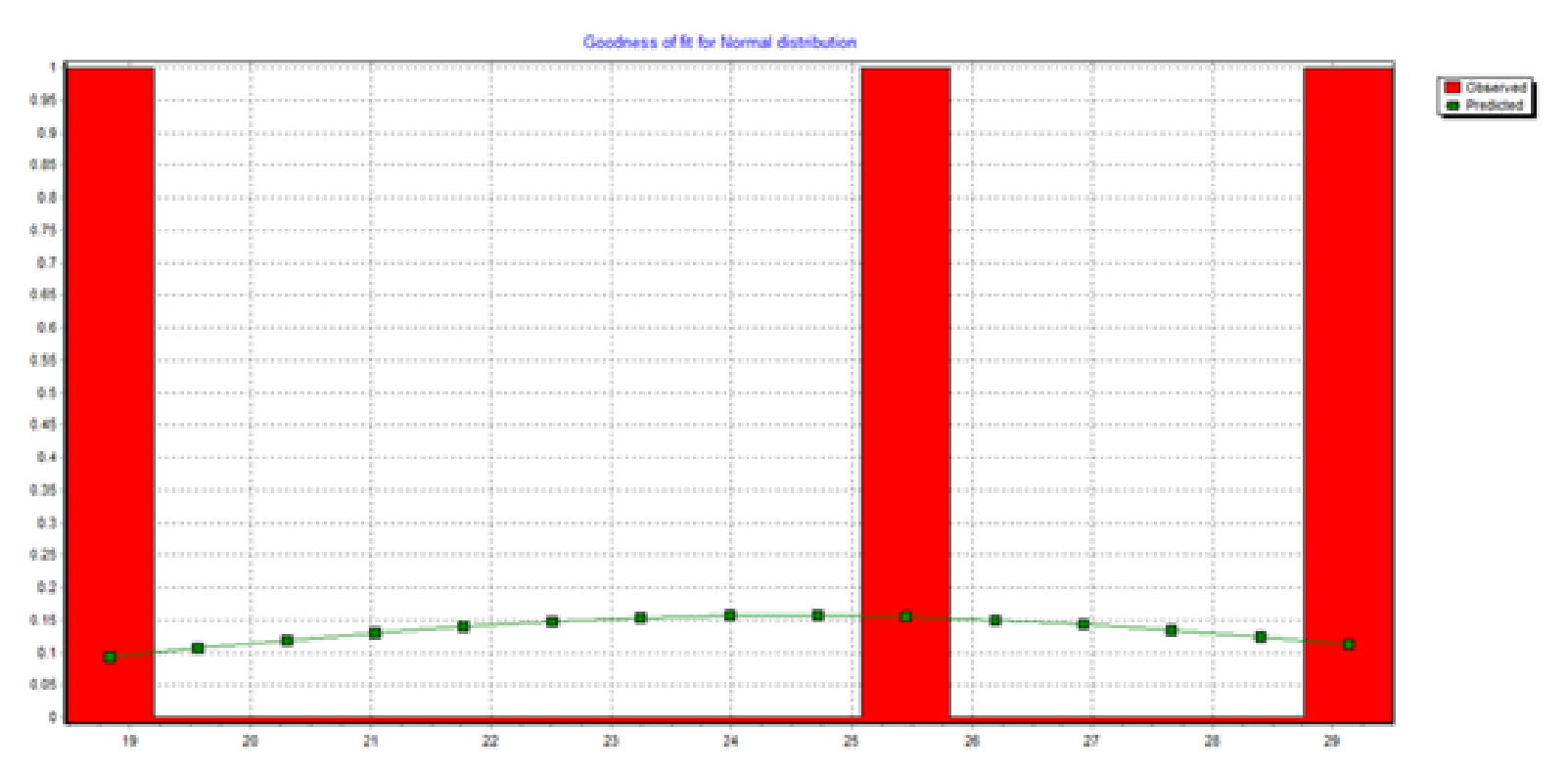

Figure I shows the tensile test of the composites. 


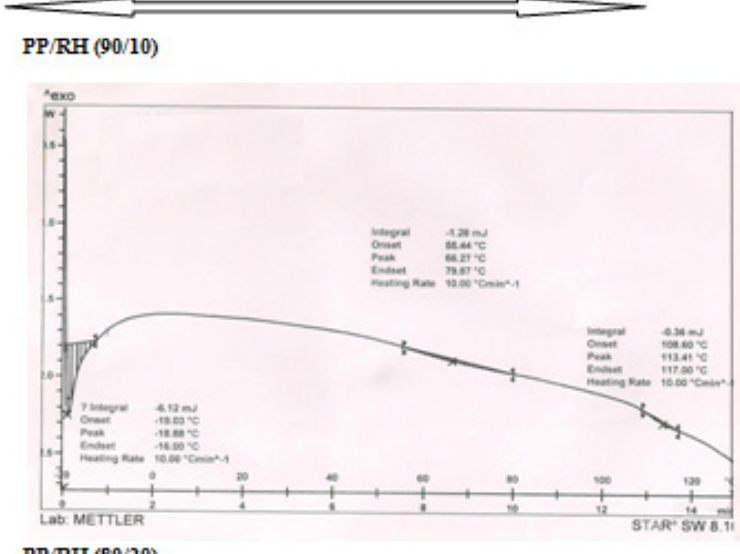

PP/RH (80/20)

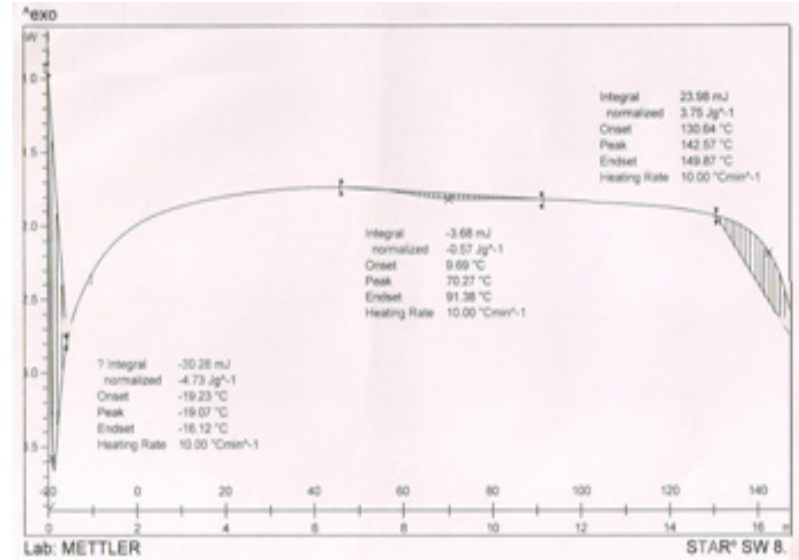

$\mathrm{PP} / \mathrm{RH}(70 / 30)$

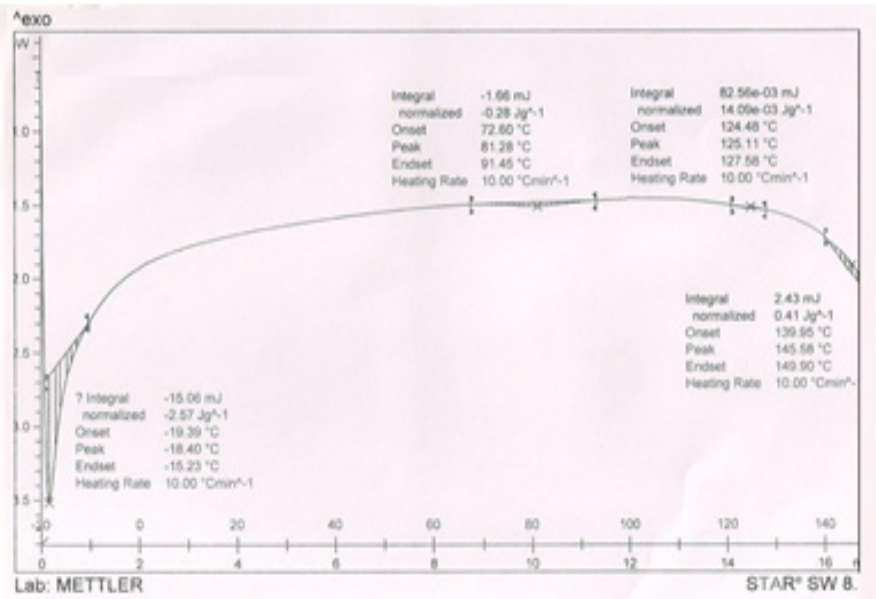

Figure 2 DSC Curves of the composites. 
Table I Typical properties of isotactic polypropylene ${ }^{12}$

\begin{tabular}{llll}
\hline S.N & Property & Unit & Value \\
\hline 1 & Tensile strength & $\mathrm{MPa}$ & 35.5 \\
2 & Tensile modulus & $\mathrm{MPa}$ & 1380 \\
4 & Elongation at break & $\%$ & $\sim 35$ \\
5 & Impact strength (izod) & $\mathrm{J} / \mathrm{m}$ & 37 \\
6 & Glass transition temperature & $\mathrm{K}$ & 278 \\
7 & Melting point & $\mathrm{K}$ & 437 \\
8 & Mould shrinkage & $\%$ & $1.0-2.5$ \\
\hline
\end{tabular}

\section{Matrix material}

Polypropylene $(\mathrm{PP})^{*}$ is a linear structured isopropane polymer composed of repeated units of isopropane. Isotactic polypropylene is a linear, higher crystalline polymer with a melting point of 438K (165 $\left.{ }^{\circ} \mathrm{C}\right)$. Its high crystallinity imparts to high tensile strength, stiffness and hardness. It has excellent resistance to acids and alkalies, but poor aromatic, aliphatic and chlorinated solvent resistance. Density of polypropylene is $915 \mathrm{~kg} / \mathrm{m}^{3}$. Impact strength of PP is very sensitive to fabrication (Figure 3). PP can be processed using all the available processing techniques: injection molding, extrusion, blow molding, thermoforming, rotational molding and spinning. ${ }^{12-13}$

Rice Husk* is biodegradable, inexpensive, low density and causes no damage to the processing machinery. Hence, it is suitable to be used as fillers in polymer matrix to form bio-composites. The very high content in amorphous silica of the husk provides it and its ash $\left(\mathrm{SiO}_{2} \sim 20 \%\right)$ vulnerable properties. ${ }^{14}$ The Rice Husk used in the present study was collected from Betul M.P. (India) in the form of agriculture residues. Isotactic Polypropylene (PP) with density 0.915 $\mathrm{gm} / \mathrm{cm}^{3}$ was obtained IPCL Vadodra.

Table lists the composites used in the study (Table 2). Varying the weight $\%$ of Treated and un treated Rice Husk $(10,20,30)$ were mechanically mixed with PP granules and compounded on a two roll mill by keeping the rollers at $200{ }^{\circ} \mathrm{C}$, weighed amount of cenosphere (treated and un treated) were mixed gradually with rice husk.

\section{Mechanical properties and density characterization \\ Density measurements}

For this test, samples were cut in to the pellet form of $2 \mathrm{~mm}$ thickness from the sheet. The density was determined by using a high precision Citizen machine, Model CX 265 as per ASTM D 792 by Archimedes principle.

\section{Mechanical properties}

Tensile testing was performed on Universal testing machine, Model-UT 10 made by Scientific Testing India as per ASTM D 638. Tensile strength, elongation and tensile modulus of the samples were determined at $10 \mathrm{~mm} / \mathrm{min}$ cross head speed.

\section{DSC characterization}

Differential Scanning Calorimetry (DSC) is the most appropriate technique to give the best information concerning melting. The change in heat capacity that occurs at the glass transition is often small (particularly for materials with low amorphous content) and there may not be enough sensitivity to detect the glass transition reliably. Differential scanning calorimetry (DSC) tests were carried out to determine melting peak temperature, onset and endset temperature by using a DSC (Mettler Toledo model DSC 822e).

\section{SEM characterization}

The surfaces for its morphological studies were first polished with gold. Many researchers, however, polish with silver or carbon. But their longevity is very less hence gold polish is preferred (silver polish oxidizes or contaminated within a few hours after formation whereas carbon polishing loses its property on attracting dust or leaves the surface with small jerks also (Table 3). Further, carbon dusts being small in size penetrate into sample and may not produce reliable results). A Scanning Electron Microscope (SEM); model JEOL JSM 5600 (Japan) was used to observe the microstructure of surfaces of particles and fibre filled composites. Composites were gold coated under vaccum as per requirement prior to surface observation.

Table 2 Composition of the composites

\begin{tabular}{lll}
\hline S.N & Sample & Nomenclature \\
1 & Pure PP & PP \\
2 & PP/Rice Husk (70/30) & PPRH30 \\
3 & PP/ Rice Husk (80/20) & PPRH20 \\
4 & PP/ Rice Husk (90/10) & PPRH10 \\
5 & PP/MATr. Rice Husk (70/30) & PPTRH30 \\
6 & PP/MATr. Rice Husk (80/20) & PPTRH20 \\
7 & PP/MATr.Rice Husk (90/10) & PPTRH10 \\
\hline
\end{tabular}


Table 3 density values of the composites

\begin{tabular}{lll}
\hline S.N & Sample & Density $(\mathbf{g} / \mathbf{c c})$ \\
\hline 1 & PP & 0.915 \\
2 & PPRH30 & 0.927 \\
3 & PPRH20 & 0.924 \\
4 & PPRH10 & 0.919 \\
5 & PPTRH30 & 0.925 \\
6 & PPTRH20 & 0.921 \\
7 & PPTRH10 & 0.910 \\
\hline
\end{tabular}
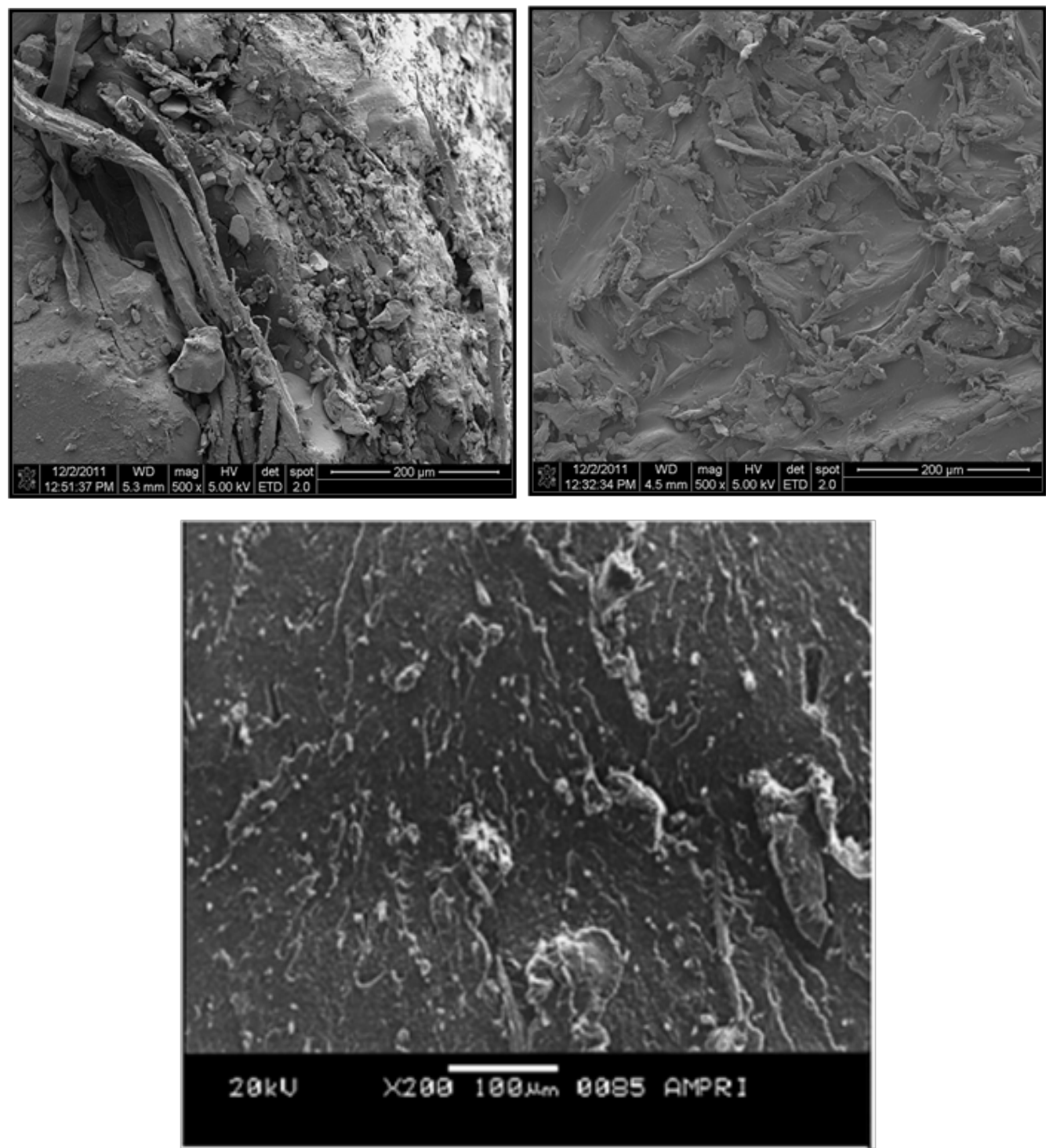

Figure 3 Photograph shows the SEM images of PP/RH composites. 


\section{Results and discussion}

It is clear that decreased with the addition of rice husk in the composites and also with the treatment of rice husk. This is due to removal of waxes from the rice husk surface

This is the Goodness of Fit curve that shows the predicted values and the observed values. Tensile measurements for the sample with composition of PP and RH are shown in the graph with the standard deviation for almost three samples of same composition. It is clear that the strength increased with the rice husk content in polypropylene but if we will go beyond $30 \%$ of rice husk results could change. This could be proved from the graphs that the bio composites prepared contains good tensile strength and less stress in the composites.

The presence of RH showed significant effects on the behavior of the composites. The DSC thermograms obtained during are shown in Figure. Only one exothermic peak was registered for all the samples. The higher temperature values of the composites indicate that the crystallization is favored in the presence of the rice husk particles. The temperature increase can be considered to be due to the nucleation effect of the rice husk: fibers act as sites for heterogeneous nucleation thus inducing the crystallization of the matrix (Figure 4). For all PP/RHF composites only one single endothermic peak was observed corresponding to the melting of the $\alpha$-crystalline phase of the PP sequences. These results indicate that the presence of $\mathrm{RH}$ did not significantly affect the crystalline structure of the polymer. The area of the melting peak diminished with increasing RH level since PP concentration in the composites lowered. However after normalizing the melting enthalpy with respect to the fraction of PP in the composites it was possible to verify that the melting peak showed a significant increase.

\section{SEM characterization}

This composite had untreated sisal fibre and untreated cenosphere filled in PP matrix. In this microphotograph inhomogenity of constituent pieces are clearly visible. The surfaces of the sisal fibre are smooth as compared to that of untreated rice husk (Table 4). The changes in the morphology of bio-degradable matrix surfaces were studied with different concentration of cassava starch with cross linked fiber matrix. It was observed that the surfaces of matrix undergoing biodegradation. Here the fracture surface of the composite has been examined by SEM analysis. Figures shows the roughness of the composites. Here surfaces become very heterogeneous and rough. It was observed that surfaces of the matrix undergoing bio-degradation which was highly roughness.

Table 4 Melting Temperature Tm $\left({ }^{\circ} \mathrm{C}\right)$, Enthalpy $\Delta \mathrm{H}(\mathrm{J} / \mathrm{g} P \mathrm{PP})$, Crystalline Temperature Tc $\left({ }^{\circ} \mathrm{C}\right)$

\begin{tabular}{lllll}
\hline $\mathbf{P P}(\mathbf{\%})$ & $\mathbf{R H F}(\mathbf{\%})$ & $\mathbf{T m}\left({ }^{\mathbf{0}} \mathbf{C}\right)$ & $\Delta \mathbf{H}(\mathbf{J} / \mathbf{g} \mathbf{P P})$ & $\mathbf{T c}\left({ }^{\mathbf{0}} \mathbf{C}\right)$ \\
\hline 90 & 10 & 164 & 91 & 119 \\
80 & 20 & 164 & 111 & 120 \\
70 & 30 & 164 & 111 & 122 \\
\hline
\end{tabular}

$\mathrm{PP} / \mathrm{RH}(70 / 30)$

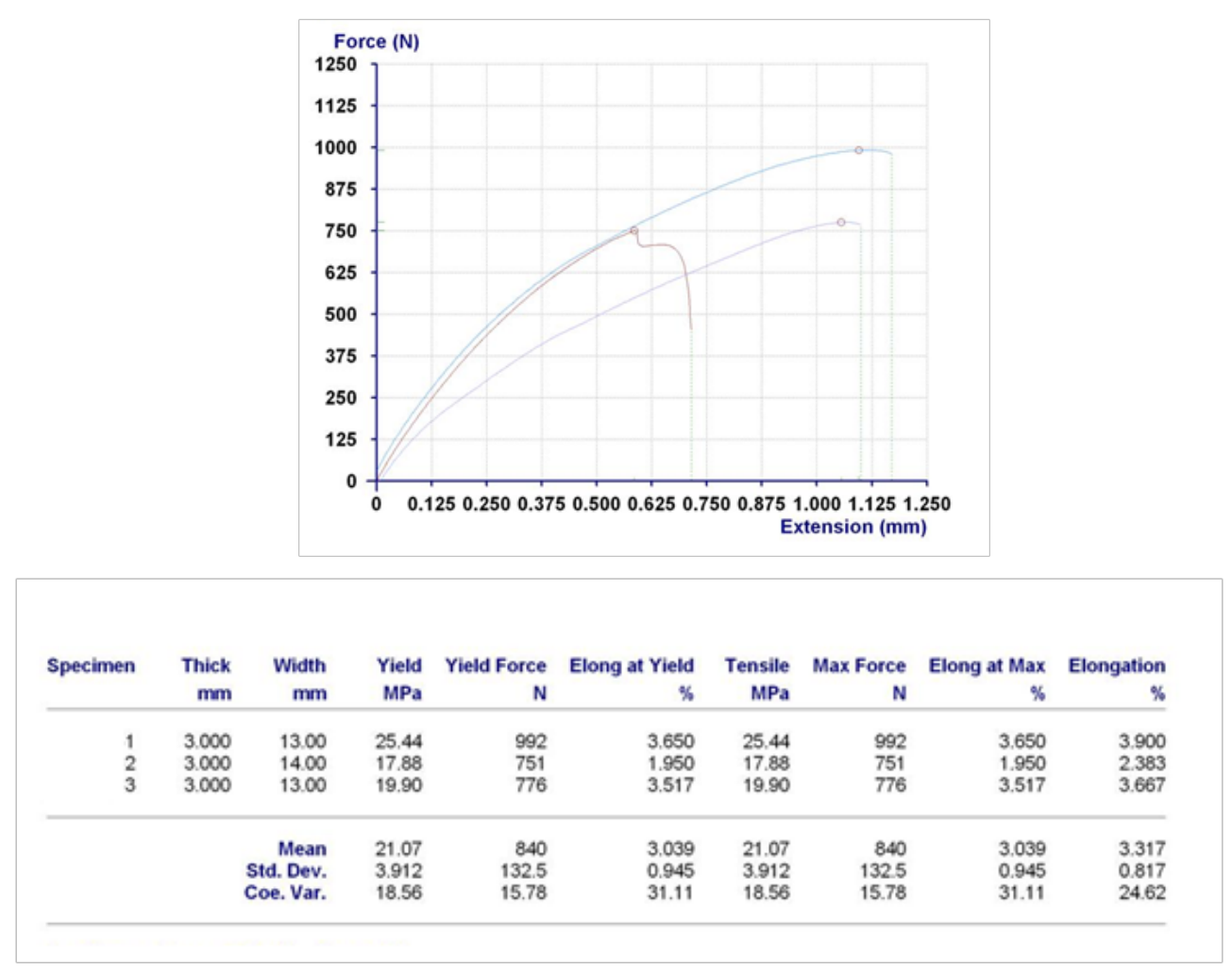




\begin{tabular}{|rrr|}
\hline Specimen & $\begin{array}{r}\text { Stress at Break } \\
\text { MPa }\end{array}$ & Force at Break \\
& & $\mathbf{N}$ \\
\hline 1 & 25.18 & 982 \\
2 & 10.78 & 453 \\
3 & 19.69 & 768 \\
& & \\
Mean & 18.55 & 734 \\
Std. Dev. & 7.27 & 266.2 \\
Coe. Var. & 39.17 & 36.25 \\
\hline
\end{tabular}

PP/RH (80/20)

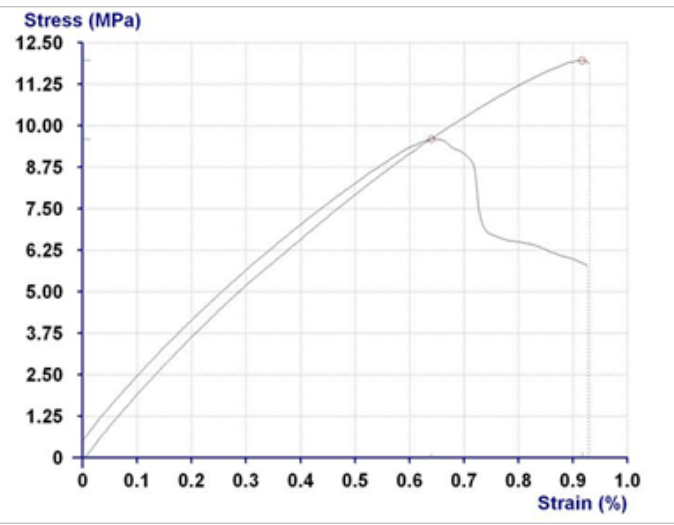

\begin{tabular}{|c|c|c|c|c|c|c|c|c|c|}
\hline Specimen & $\begin{array}{r}\text { Thick } \\
\text { mm }\end{array}$ & $\begin{array}{r}\text { Width } \\
\text { mm }\end{array}$ & $\begin{array}{r}\text { Yield } \\
\text { MPa }\end{array}$ & $\begin{array}{r}\text { Yield Force } \\
\mathrm{N}\end{array}$ & $\begin{array}{r}\text { Elong at Yield } \\
\%\end{array}$ & $\begin{array}{r}\text { Tensile } \\
\mathrm{MPa}\end{array}$ & $\begin{array}{r}\text { Max Force } \\
\mathrm{N}\end{array}$ & $\begin{array}{r}\text { Elong at Max } \\
\%\end{array}$ & $\begin{array}{r}\text { Elongation } \\
\% \\
\end{array}$ \\
\hline $\begin{array}{l}1 \\
2\end{array}$ & $\begin{array}{l}3.000 \\
3.000\end{array}$ & $\begin{array}{l}12.50 \\
12.50\end{array}$ & $\begin{array}{r}11.97 \\
9.60\end{array}$ & $\begin{array}{l}449.0 \\
360.0\end{array}$ & $\begin{array}{l}0.917 \\
0.640\end{array}$ & $\begin{array}{r}11.97 \\
9.60\end{array}$ & $\begin{array}{l}449.0 \\
360.0\end{array}$ & $\begin{array}{l}0.917 \\
0.640\end{array}$ & $\begin{array}{l}0.930 \\
0.927\end{array}$ \\
\hline & & $\begin{array}{l}\text { Mean } \\
\text { Std. Dev. } \\
\text { Coe. Var. }\end{array}$ & $\begin{array}{l}10.79 \\
1.678 \\
15.56\end{array}$ & $\begin{array}{r}404.5 \\
62.9 \\
15.56\end{array}$ & $\begin{array}{r}0.778 \\
0.1956 \\
25.13\end{array}$ & $\begin{array}{l}10.79 \\
1.678 \\
15.56\end{array}$ & $\begin{array}{r}404.5 \\
62.9 \\
15.56\end{array}$ & $\begin{array}{r}0.778 \\
0.1956 \\
25.13\end{array}$ & $\begin{array}{r}0.928 \\
0.0024 \\
0.2539\end{array}$ \\
\hline
\end{tabular}

\begin{tabular}{rrr}
\hline Specimen & $\begin{array}{r}\text { Stress at Break } \\
\text { MPa }\end{array}$ & $\begin{array}{r}\text { Force at Break } \\
\mathbf{N}\end{array}$ \\
& 11.85 & 444.5 \\
2 & 5.78 & 216.7 \\
& & \\
Mean & 8.82 & 330.6 \\
Std. Dev. & 4.295 & 161.1 \\
Coe. Var. & 48.72 & 48.72 \\
\hline
\end{tabular}

PP/RH (90/10)

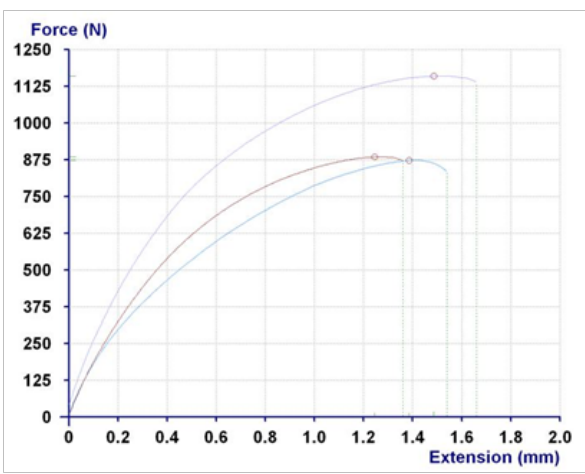

Citation: Sharma J, Sajjad A, Bhat U, et al.An approach to use agricultural waste fibre in polymer (polypropylene: PP) for bio-composites applications. Material Sci \& Eng Int J. 20I8;2(5): I49-I57. DOI: I0.15406/mseij.2018.02.00049 


\begin{tabular}{|c|c|c|c|c|c|c|c|c|c|}
\hline Specimen & $\begin{array}{r}\text { Thick } \\
\text { mm }\end{array}$ & $\begin{array}{r}\text { Width } \\
\mathrm{mm}\end{array}$ & $\begin{array}{r}\text { Yield } \\
\text { MPa }\end{array}$ & $\begin{array}{r}\text { Yield Force } \\
\mathrm{N}\end{array}$ & $\begin{array}{r}\text { Elong at Yield } \\
\%\end{array}$ & $\begin{array}{r}\text { Tensile } \\
\text { MPa }\end{array}$ & $\begin{array}{r}\text { Max Force } \\
\mathrm{N}\end{array}$ & $\begin{array}{r}\text { Elong at Max } \\
\%\end{array}$ & $\begin{array}{r}\text { Elongation } \\
\% \\
\end{array}$ \\
\hline \multirow[t]{2}{*}{$\begin{array}{l}1 \\
2 \\
3\end{array}$} & $\begin{array}{l}2.800 \\
2.800 \\
2.800\end{array}$ & $\begin{array}{l}12.00 \\
13.00 \\
14.00\end{array}$ & $\begin{array}{l}25.98 \\
24.31 \\
29.59\end{array}$ & $\begin{array}{r}873 \\
885 \\
1160\end{array}$ & $\begin{array}{l}4.620 \\
4.150 \\
4.953\end{array}$ & $\begin{array}{l}25.98 \\
24.31 \\
29.59\end{array}$ & $\begin{array}{r}873 \\
885 \\
1160\end{array}$ & $\begin{array}{l}4.620 \\
4.150 \\
4.953\end{array}$ & $\begin{array}{l}5.13 \\
4.53 \\
5.53\end{array}$ \\
\hline & \multicolumn{2}{|r|}{$\begin{array}{l}\text { Mean } \\
\text { Std. Dev. } \\
\text { Coe. Var. }\end{array}$} & $\begin{array}{l}26.63 \\
2.698 \\
10.13\end{array}$ & $\begin{array}{r}973 \\
162.3 \\
16.69\end{array}$ & $\begin{array}{r}4.574 \\
0.4036 \\
8.82\end{array}$ & $\begin{array}{l}26.63 \\
2.698 \\
10.13\end{array}$ & $\begin{array}{r}973 \\
162.3 \\
16.69\end{array}$ & $\begin{array}{r}4.574 \\
0.4036 \\
8.82\end{array}$ & $\begin{array}{r}5.07 \\
0.502 \\
9.92\end{array}$ \\
\hline & \multicolumn{3}{|c|}{ Specimen } & Stress & $\begin{array}{r}\text { at Break } \\
\text { MPa }\end{array}$ & \multicolumn{2}{|c|}{$\begin{array}{r}\text { Force at Break } \\
\mathrm{N}\end{array}$} & $\begin{array}{r}\mathrm{ak} \\
\mathrm{N}\end{array}$ & \\
\hline & & & $\begin{array}{l}1 \\
2 \\
3\end{array}$ & & $\begin{array}{l}24.85 \\
23.93 \\
29.05\end{array}$ & & $\begin{array}{r}\varepsilon \\
8 \\
11\end{array}$ & $\begin{array}{l}35 \\
71 \\
39\end{array}$ & \\
\hline & & \multicolumn{2}{|c|}{$\begin{array}{l}\text { Mean } \\
\text { Std. Dev. } \\
\text { Coe. Var. }\end{array}$} & & $\begin{array}{l}25.94 \\
2.730 \\
10.52\end{array}$ & & $\begin{array}{r}c \\
16 \\
17\end{array}$ & $\begin{array}{r}48 \\
6.0 \\
50\end{array}$ & \\
\hline
\end{tabular}

Stress Range: 100 MPA

Strain Range: $20 \%$

Gauge Length: $30 \mathrm{~mm}$

Test Speed: $10 \mathrm{~mm} / \mathrm{min}$

Figure 4 Tensile Test parameters are as follows.

\section{Conclusion}

In this study, we synthesized polypropylene based biocomposite and studied the structural parameter of the fiber with the correlation to morphological and thermal properties of the composites by varying rice husk concentration. SEM microstructure for the composite shows good adhesion between fiber and matrix. DSC analysis conforms that to increase in the rice husk concentration in the composite the glass transition temperature increases. Higher the percentage of rice husk in composite increases the free volume and molecular mobility, which results in increasing of $\mathrm{Tg}$. Increase in $\mathrm{Tg}$ indicates that composites change from rubbery to crystalline phase. Non-food crops and other biorenewable resources offer an almost limitless supply of renewable and potentially sustainable raw materials for the production of biocomposites. Although in its infancy, there is a growing market for biocomposite-based products and with further development a whole host of new applications can be envisioned. There is a huge range of potential reinforcing fibres/fillers and an extensive range of processing options to ensure the right fibre at the right price. Improved tensile strength is observed for the $30 \%$ rice husk composition.

\section{Acknowledgments}

None.

\section{Conflict of interest}

Author declares there is no conflict of interest.

\section{References}

1. Karpinos DM. Hand Book of Composite Materials. Kiev; 1985.

2. Richardson M. Industrial Polymer Composite Materials. Khimiya, Moscow; 1980.

3. Singh RA, Gupta K, Singh SK, et al. Preparation and characterization of polymer composites based on charge-transfer complex of phenothiazineiodine in polystyrene. Bull Mater Sci. 2005;28(5):423-429.

4. Broutman LJ, Krock RH. Modern Composite Materials. Addison-Wesley Publishing Company, London; 1967.

5. Ichao MN, Albano C, Gonzalez J, et al. Composite Structure. 2001;54(23):207-214.

6. Bledzki, Gassan J. Composites Reinforced with Cellulose Based Fibres. Progress in Polymer Science. 1999;24:221-274.

7. Zafeiropoulos NE, Williams DR, Baillie CA, et al. Composites, Part A: Applied Science and Manufacturing. 2002;33:1083-1093.

8. Dhyani KC, Geopaul N. Jute Bulletin. 1974. p. 226-228.

9. Jillek W, Yung WKC. Embedded components in printed circuit boards: a processing technology review. International Journal Manufacturing Technology. 2005;25(4):350-355.

10. Ulrich R. IEEE, Transactions in Advanced Package. 2004;27:326-330.

11. Kuo DH, Chang CC, Su TY. Journal of European ceramic society. 2002;21:1171-1179.

12. Natta G, Pino P, Corradini P. Crystalline high polymers of $\alpha$-olefins. Journal of American Chemical Society. 1955;77:1708-1716. 
13. Verbicky JW. In: Mark HF, Bides NM, editors. John Wiley and Sons, New York; 1988;12.
14. Perepelkin KE. St. Petersburg state University of Technology and Design. Khimicheskie Volokna, editor. 2005;4:7-22. 